\title{
Effects of G6pc2 deletion on body weight and cholesterol in mice
}

Kayla A Boortz', Kristen E Syring', Lynley D Pound', Huan Mo², Lisa Bastarache²,
James K Oeser', Owen P McGuinness', Joshua C Denny',3 and Richard M O'Brien'

1Department of Molecular Physiology and Biophysics, Vanderbilt University School of Medicine, Nashville, Tennessee, USA

2Department of Biomedical Informatics, Vanderbilt University School of Medicine, Nashville, Tennessee, USA

${ }^{3}$ Department of Medicine, Vanderbilt University School of Medicine, Nashville, Tennessee, USA
Correspondence should be addressed to R M O'Brien Email

richard.obrien@vanderbilt. edu

\begin{abstract}
Genome-wide association study (GWAS) data have linked the G6PC2 gene to variations in fasting blood glucose (FBG). G6PC2 encodes an islet-specific glucose-6-phosphatase catalytic subunit that forms a substrate cycle with the beta cell glucose sensor glucokinase. This cycle modulates the glucose sensitivity of insulin secretion and hence FBG. GWAS data have not linked G6PC2 to variations in body weight but we previously reported that female C57BL/6J G6pc2-knockout (KO) mice were lighter than wild-type littermates on both a chow and high-fat diet. The purpose of this study was to compare the effects of G6pc2 deletion on FBG and body weight in both chow-fed and highfat-fed mice on two other genetic backgrounds. FBG was reduced in G6pc2 KO mice largely independent of gender, genetic background or diet. In contrast, the effect of $G 6 p c 2$ deletion on body weight was markedly influenced by these variables. Deletion of $66 p c 2$ conferred a marked protection against diet-induced obesity in male mixed genetic background mice, whereas in 129SvEv mice deletion of G6pc2 had no effect on body weight. G6pc2 deletion also reduced plasma cholesterol levels in a manner dependent on gender, genetic background and diet. An association between G6PC2 and plasma cholesterol was also observed in humans through electronic health recordderived phenotype analyses. These observations suggest that the action of G6PC2 on FBG is largely independent of the influences of environment, modifier genes or epigenetic events, whereas the action of G6PC2 on body weight and cholesterol are influenced by unknown variables.
\end{abstract}

Journal of Molecular Endocrinology (2017) 58, 127-139

\section{Introduction}

The glucose-6-phosphatase (G6Pase) enzyme system is located in the endoplasmic reticulum and catalyzes the hydrolysis of glucose-6-phosphate (G6P) to glucose and inorganic phosphate (Hutton \& O'Brien 2009, O'Brien 2013). In addition to a catalytic subunit, which can be one of three isoforms, G6PC1, G6PC2 or G6PC3, the
G6Pase system is composed of a glucose transporter and a G6P/Pi transporter, encoded by the SLC37A4 gene (Hutton \& O'Brien 2009, O'Brien 2013). G6PC2 is thought to be expressed exclusively in pancreatic islet beta cells (Hutton \& O'Brien 2009, O'Brien 2013). Experiments comparing wild-type (WT) and G6pc2-knockout (KO) http://jme.endocrinology-journals.org DOI: 10.1530/JME-16-0202
C) 2017 Society for Endocrinology Printed in Great Britain
Published by Bioscientifica Ltd 
mouse islets suggest that G6pc2 opposes the action of the beta cell glucose sensor, glucokinase, which catalyzes the formation of G6P from glucose (Matschinsky 2005, Iynedjian 2009). In isolated G6pc2 $\mathrm{KO}$ islets, G6Pase activity (Pound et al. 2013) and glucose cycling (Wall et al. 2015) are abolished. This results in a leftward shift in the dose-response curve for glucose-stimulated insulin secretion (GSIS) (Pound et al. 2013). Under fasting conditions, where insulin levels are the same in WT and G6pc2 KO mice, this shift results in reduced fasting blood glucose (FBG) in KO mice (Wang et al. 2007, Pound et al. 2013, Boortz et al. 2016). In contrast, under stimulatory conditions using a sub-maximal concentration of glucose, this shift results in increased GSIS from G6pc2 KO relative to WT mouse islets (Pound et al. 2013). As predicted from a parallel shift in the dose-response curve for GSIS, under stimulatory conditions using a high concentration of glucose, this shift results no difference in GSIS between G6pc2 KO and WT as assessed in either isolated islets in situ (Pound et al. 2013) or mice in vivo using hyperglycemic clamps (Wang et al. 2007).

Consistent with these mouse studies, genome-wide association studies (GWAS) have linked the rs560887 single nucleotide polymorphism (SNP) in the G6PC2 gene to variations in FBG (Bouatia-Naji et al. 2008, Chen et al. 2008). Molecular studies have shown that the rs560887-G allele represents a gain of function that is associated with increased G6PC2 RNA splicing, which is predicted to lead to increased full-length G6PC2 protein expression and elevated glucose cycling (Baerenwald et al. 2013). As GWAS data show that the rs560887-G allele is associated with elevated FBG (Bouatia-Naji et al. 2008, Chen et al. 2008), the combination of these splicing (Baerenwald et al. 2013) and G6pc2 KO mouse (Wang et al. 2007, Pound et al. 2013) studies suggest that rs560887 is a potentially causative variant. The association between G6PC2 and FBG has been confirmed in multiple GWAS and in different populations (Prokopenko et al. 2008, Bouatia-Naji et al. 2009, Hu et al. 2009, 2010, Reiling et al. 2009, Dupuis et al. 2010, Tam et al. 2010, Wang et al. 2013).

Numerous GWAS have also examined the genes that are associated with variations in body weight, fat mass and fat distribution and have shown that greater than 160 loci are linked to these parameters (Lu et al. 2016). Although G6PC2 was not one of the loci identified (Lu et al. 2016), we previously observed that female C57BL/6J G6pc2 KO mice were lighter than wild-type (WT) littermates on both a chow-fed and high-fat-fed diet (Pound et al. 2013). This observation prompted us to examine whether genetic background influences the effect of G6pc2 deletion on body weight and the response to diet-induced obesity (DIO). The results show that the effect of G6pc2 deletion on FBG is largely independent of gender, genetic background and diet, whereas the effect of $G 6 p c 2$ deletion on body weight is highly dependent on these variables. We also found that deletion of G6pc2 reduced plasma cholesterol levels in a manner dependent on gender, genetic background and diet. These observations suggest that the action of G6PC2 on FBG is largely unaffected by the influences of environment, gender, modifier genes or epigenetic events, whereas the action of G6PC2 on body weight and cholesterol are influenced by unknown variables.

\section{Materials and methods}

\section{Animal care}

The Vanderbilt University Medical Center Animal Care and Use Committee approved all protocols used. Mice were maintained on either a standard rodent chow diet (calorie contributions: $28 \%$ protein, $12 \%$ fat, $60 \%$ carbohydrate (14\% disaccharides); LabDiet 5001; PMI Nutrition International) or a high-fat diet (calorie contributions: $15 \%$ protein, $59 \%$ fat, $26 \%$ carbohydrate (42\% disaccharides); Mouse Diet F3282; BioServ). High-fat feeding studies were initiated at 8 weeks of age, and mice were maintained on the diet for 8-14 weeks as indicated. Food and water were provided ad libitum.

\section{Generation of G6pc2-knockout (KO) mice}

Previous studies have described the generation of G6pc2 KO mice on a mixed $129 \mathrm{SvEV} \times \mathrm{C} 57 \mathrm{BL} / 6 \mathrm{~J}$ (Wang et al. 2007), C57BL/6J (Pound et al. 2013) and 129SvEv (Boortz et al. 2016) genetic background. The targeting vector used to generate the $\mathrm{KO}$ allele replaced exons $1-3$ of the G6pc2 gene with a LacZ/Neo cassette leaving exons 4 and 5 intact (Wang et al. 2007). Exon 1 contains the translation initiation methionine (Ebert et al. 1999). As such, the design of the targeting vector completely abolishes G6pc2 expression (Wang et al. 2007). All the mice examined in these studies were littermates generated by interbreeding of heterozygous (HET) mice.

\section{Intraperitoneal glucose tolerance tests}

Intraperitoneal glucose tolerance tests (IPGTTs) were performed on 22 -week-old male mice as previously described (Pound et al. 2012).

Published by Bioscientifica Ltd. 


\section{Phenotypic analysis of fasted G6pc2 KO mice}

Mice were fasted for $5 \mathrm{~h}$ and then weighed. After an additional hour of fasting, mice were anesthetized using isoflurane, and blood samples were isolated from the retro-orbital venous plexus. Glucose concentrations were measured in whole blood using a glucose monitor (Accu-Check Advantage; Roche). EDTA ( $5 \mu \mathrm{L} ; 0.5 \mathrm{M})$ was then added to blood samples prior to the isolation of plasma by centrifugation. Insulin samples were assayed using RIA (Morgan \& Lazarow 1963) by the Vanderbilt Hormone Assay and Analytical Services Core. Cholesterol was assayed using a cholesterol reagent kit (Raichem, San Diego, CA, USA), whereas triacylglycerol was assayed using a serum triacylglycerol determination kit (Sigma). Body composition was assessed using an mq10 NMR analyzer (Bruker Optics).

\section{Analysis of gene expression in mouse pancreas}

Pancreatic gene expression was analyzed as previously described (Boortz et al. 2016). The following mouse primer pairs were used for the analysis of gene expression:

G6pc2 forward 5'-CCCTGATGGTGGTGGCTCTA-3'

G6pc2 reverse 5'-GTCTGTGGGTGGAGCAGGAC-3'

Ins 2 forward 5'-CACCCAGGCTTTTGTCAAGC-3'

Ins2 reverse 5'-CCAGTGCCAAGGTCTGAAGG-3'

Mouse Ppia forward 5'-GGCCGATGACGAGCCC-3'

Mouse Ppia reverse 5'-TGTCTTTGGAACTTTGTCTGCAA-3'

\section{Electronic health record (EHR)-based phenotyping of human research subjects}

EHR-based phenotyping was conducted using data on human subjects in the Vanderbilt University Medical Center (VUMC) BioVU DNA databank. Genotyping data in BioVU is linked to the synthetic derivative (SD), a de-identified version of the VUMC EHR repository. Detailed descriptions of program operations, ethical considerations and continuing oversight and patient engagement have been published (Roden et al. 2008, Pulley et al. 2010). For these studies, we used a previously genotyped cohort of 29,722 European descendants from VUMC with longitudinal medical care. Genotyping was performed on the Illumina Human Exome BeadChip platform. For this study, we specifically analyzed the intronic G6PC2 SNP rs560887. Lipid measurements utilized routine clinical laboratory testing values present in the EHR.

\section{Statistical analyses}

Other than IPGTTs, data were analyzed using a Student's t-test: two sample assuming equal variance. The level of significance was as indicated (two-sided Student's $t$-test). IPGTT data were analyzed using a two-way ANOVA assuming normal distribution and equal variance. A post hoc analysis was performed using the Bonferroni correction for multiple comparisons. The level of significance was as indicated.

To analyze genetic associations with lipids in BioVU, we used the median value for each individual. The associations between the genotypes and the aggregated laboratory values (as continuous variables) were performed on $\mathrm{R}$ with linear model, adjusted for age, sex and body mass index (BMI). We report beta values, 95\% confidence intervals $(\mathrm{CI})$ and $P$ values. $P<0.05$ was considered to be significant. All tests assumed a twotailed distribution.

\section{Results}

Analysis of the effect of G6pc2 deletion on body weight and composition in chow- and high-fat-fed 129SvEv mice

We have previously shown that 16-week-old chow-fed female, but not male, C57BL/6J G6pc2-knockout (KO) mice are slightly lighter than wild-type (WT) littermates and have reduced body fat (Pound et al. 2013). These differences were also observed following 12 weeks of highfat feeding in female, but not male, C57BL/6J G6pc2 KO mice (Pound et al. 2013). In this study, we repeated these analyses with G6pc2 KO mice on a 129SvEv or mixed genetic background.

In 16-week-old chow-fed 129SvEv G6pc2 mice, no differences in weight or body fat were observed between female WT or KO mice (Table 1). However, male chowfed 129SvEv G6pc2 KO mice were slightly lighter than WT littermates, and female chow-fed 129SvEv G6pc2 KO mice had slightly increased muscle mass (Table 1).

High-fat feeding is a standard nutritional challenge in the field of obesity and diabetes research that induces insulin resistance and is considered to model human disease (Young \& Kirkland 2007). High-fat feeding of $129 \mathrm{SvEv}$ mice was started at 8 weeks of age and continued for 12 weeks. In contrast to C57BL/6J mice that markedly increase their body weight in response to high-fat feeding (Surwit et al. 1988, Winzell \& Ahren 2004, Pound et al. 2013) almost no difference in body weight was observed between 16-week-old

Published by Bioscientifica Ltd. 
Table 1 NMR analysis of chow-fed 129SvEv G6pc2 KO mouse body composition.

\begin{tabular}{|c|c|c|c|c|c|c|c|}
\hline $\begin{array}{l}\text { Gender } \\
\text { and } \\
\text { genotype }\end{array}$ & Body weight (g) & Fat $(\mathrm{g})$ & Muscle (g) & Free fluid (g) & Fat $(\%)$ & Muscle (\%) & Free fluid (\%) \\
\hline $\begin{array}{l}\text { Female } \\
\text { WT }\end{array}$ & $22.23 \pm 0.26(15)$ & $2.76 \pm 0.26(11)$ & $13.94 \pm 0.27(11)$ & $0.58 \pm 0.05(11)$ & $13.04 \pm 1.15(11)$ & $66.32 \pm 0.94(11)$ & $2.78 \pm 0.26(11)$ \\
\hline $\begin{array}{l}\text { Female } \\
\mathrm{KO}\end{array}$ & $22.11 \pm 0.54(14)$ & $3.09 \pm 0.46(9)$ & $14.69 \pm 0.25(9) *$ & $0.60 \pm 0.03(9)$ & $13.48 \pm 1.62(9)$ & $66.05 \pm 1.34(9)$ & $2.71 \pm 0.15(9)$ \\
\hline Male WT & $28.47 \pm 0.34(16)$ & $2.02 \pm 0.35(11)$ & $19.23 \pm 0.37(11)$ & $0.82 \pm 0.10(11)$ & $7.40 \pm 1.29(11)$ & $69.90 \pm 0.91(11)$ & $2.96 \pm 0.25(11)$ \\
\hline Male KO & $26.93 \pm 0.54(12) *$ & $1.51 \pm 0.25(9)$ & $18.21 \pm 0.38$ & $0.75 \pm 0.12(9)$ & $6.03 \pm 1.00(9)$ & $72.45 \pm 0.96(9)$ & $3.01 \pm 0.51$ \\
\hline
\end{tabular}

Body composition of 6-h fasted, 16-week-old animals was assessed using a mq10 NMR analyzer. Results are means \pm S.E.M. obtained from the number of animals indicated in parentheses.

Weight: ${ }^{*} P<0.009$ male WT vs KO; Muscle: ${ }^{*} P<0.04$ female WT vs KO.

KO, knockout; WT, wild type.

chow-fed female and male 129SvEv mice (Table 1) vs 20-week-old high-fat-fed female and male 129SvEv mice (Table 2). Weekly measurements of body weight in nonfasted high-fat-fed mice during the 12 weeks of highfat feeding showed no evidence for a biphasic change in weight, that would have been suggestive of a toxic effect of prolonged high-fat feeding, in either female (Fig. 1A) or male (Fig. 1B) WT and KO mice. These data are consistent with previous studies that have observed that 129SvEv mice are resistant to DIO (Almind \& Kahn 2004).

Despite the lack of weight gain, high-fat-fed female and male $129 \mathrm{SvEv}$ mice showed a marked increase in body fat (\%) relative to chow-fed mice (Fig. 1C). This was associated with a reduction in body muscle (\%) in both high-fat-fed female and male 129SvEv mice (Table 2) relative to chow-fed female and male mice (Table 1) $(P<0.05)$.

In 20-week-old high-fat-fed 129SvEv G6pc2 mice, no differences in body fat were observed between female or male WT vs KO mice (Table 2). However, male high-fat-fed 129SvEv G6pc2 KO mice were slightly heavier than WT littermates, and free fluid was reduced in female high-fat-fed 129SvEv G6pc2 KO mice (Table 2).

\section{Analysis of the effect of G6pc2 deletion on fasting blood glucose (FBG) and fasting plasma insulin (FPI) in high-fat- fed 129SvEv mice}

We have previously shown that male $129 \mathrm{SvEv}$ G6pc2 KO mice have reduced FBG but no change in FPI relative to WT littermates (Boortz et al. 2016). When this analysis was repeated using female $129 \mathrm{SvEv}$ chow-fed mice, this same reduction in FBG was observed in G6pc2 $\mathrm{KO}$ mice (Fig. 1D) with no change in FPI (Fig. 1E).

We next analyzed the effect of high-fat feeding on FBG and FPI in 129SvEv mice. Despite 13 weeks of high-fat feeding, a comparison between female (Fig. 1D) and male (Boortz et al. 2016) chow fed with female (Fig. 1F) and male (Fig. 1G) high-fat fed 129SvEv WT mice revealed surprisingly no increase in FBG. Similarly, a comparison between female (Fig. 1E) and male (Boortz et al. 2016) chow-fed with female

Table 2 NMR analysis of high-fat-fed 129SvEv G6pc2 KO mouse body composition.

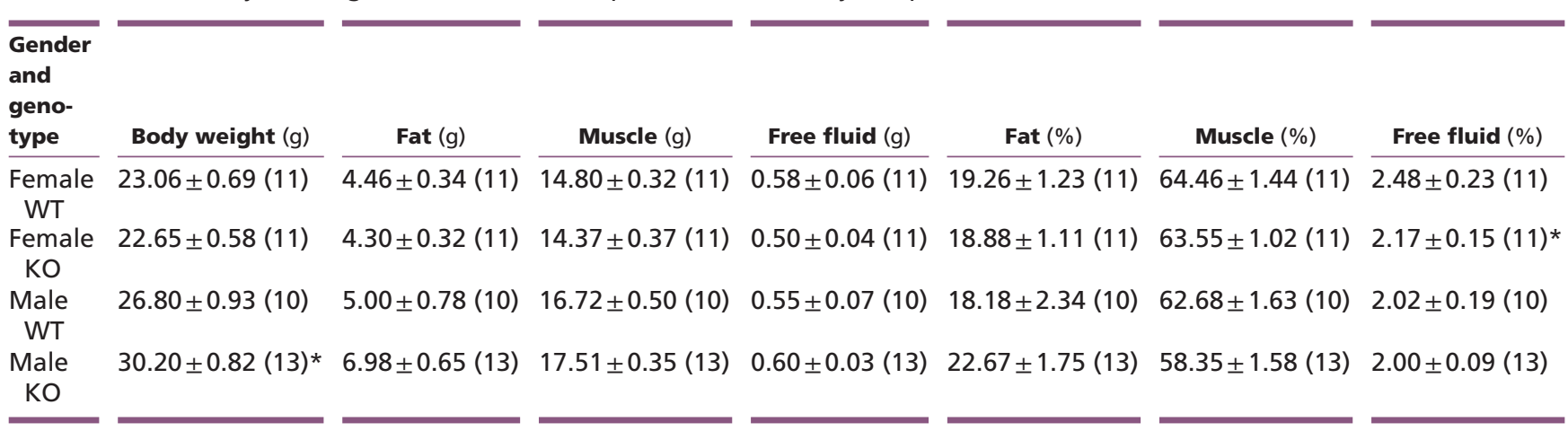

Body composition of 6-h fasted, 20-week-old animals after 12 weeks of high-fat feeding was assessed using a mq10 NMR analyzer. Results are means \pm S.E.M. obtained from the number of animals indicated in parentheses.

Weight: ${ }^{*} P<0.0124$ WT vs KO.

KO, knockout; WT, wild type. 
A

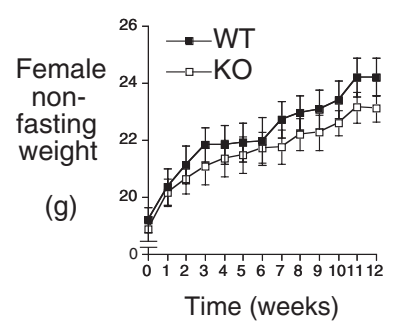

D

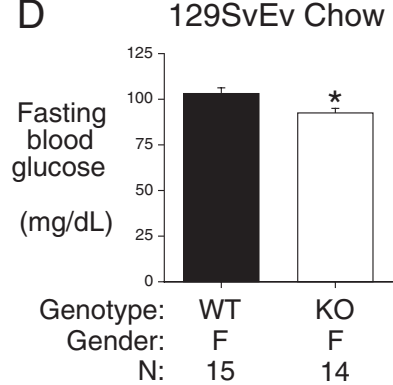

$\mathrm{H}$
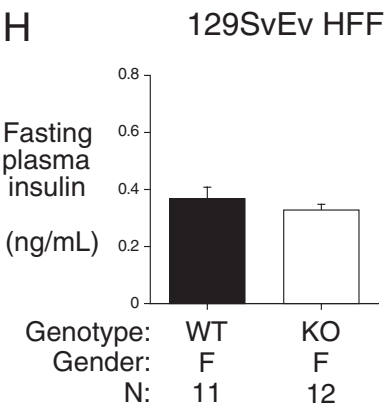

B

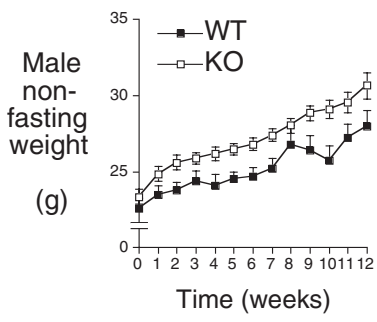

E

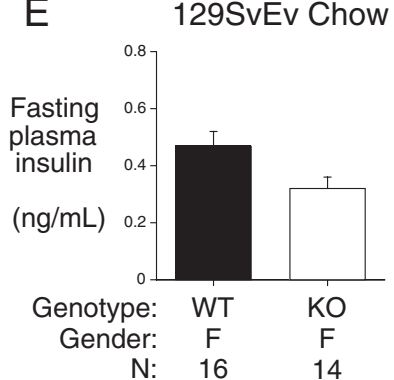

I

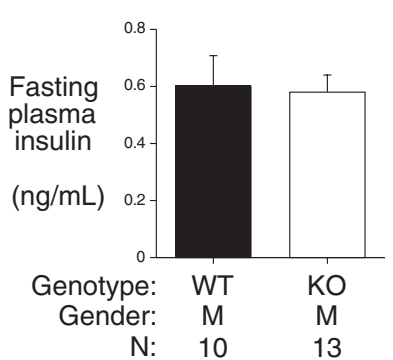

C

129SvEv HFF

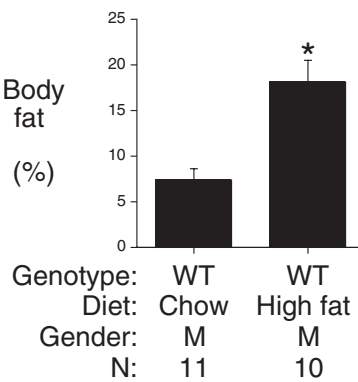

G

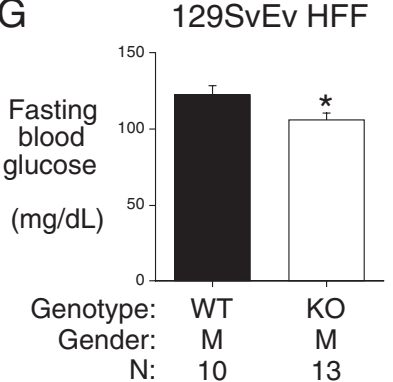

Figure 1

Effect of G6pc2 deletion on body weight, composition and metabolic parameters in chow-fed and high-fat-fed 129SvEv mice. Panels A and B: Starting at 8 weeks of age, female (Panel A) and male (Panel B) mice were fed a high-fat diet with non-fasting body weights measured weekly. Results are the mean \pm S.E.M. of data from the following number of animals: female WT $n=12 ;$ female KO $n=13$; male WT $n=10$; male KO $n=13$. Panel C: Body composition was assessed in chow-fed 129SvEv mice at 16 weeks of age and in high-fat-fed $129 \mathrm{SvEv}$ mice at 20 weeks of age after 12 weeks of high-fat feeding. Mice were fasted for $5 \mathrm{~h}$ and then weighed. One hour later, body fat was determined by NMR. Results are the mean \pm S.E.M. of data with the genotype, gender and number of animals indicated. WT, wild type; F, female; M, male. ${ }^{*} P<4.61 \mathrm{E}-10$ high-fat-fed vs chow-fed females; $* P<3.94 \mathrm{E}-05$ high-fat-fed vs chow-fed males. Panels $\mathrm{D}$ and $\mathrm{E}$ : At 17 weeks of age, chow-fed mice were fasted for $5 \mathrm{~h}$ and then weighed. One hour later, mice were anesthetized and blood was isolated. Blood glucose (Panel D) and plasma insulin (Panel E) were determined as described in the 'Materials and methods' section. Results are the mean \pm S.E.M. of data with the genotype, gender and number of animals indicated. WT, wild type; KO, knockout; F, female. ${ }^{*} P<0.014$ WT vs KO (Panel D). Panels F, G, H and I: Metabolic parameters were assessed in high-fat-fed 129SvEv mice at 21 weeks of age after 13 weeks of high-fat feeding. Mice were fasted for $5 \mathrm{~h}$ and then weighed. One hour later, mice were anesthetized and blood was isolated. Blood glucose (Panels F and G) and plasma insulin (Panels $\mathrm{H}$ and $\mathrm{I}$ ) were determined as described in the 'Materials and methods' section. Results are the mean \pm S.E.M. of data with the genotype, gender and number of animals indicated. WT, wild type; KO, knockout; F, female; $\mathrm{M}$, male. ${ }^{*} P<0.001$ female WT vs KO (Panel F); ${ }^{*} P<0.037$ male WT vs KO (Panel G). Panel J: Glucose tolerance was assessed in chow-fed 129SvEv at 22 weeks of age and in high-fat-fed 129SvEv mice at 22 weeks of age after 13 weeks of high fat feeding. IPGTTs using $2.0 \mathrm{~g} / \mathrm{kg}$ glucose were performed on 6-h fasted, conscious, chow- or high-fat-fed wild-type (WT) and G6pc2-knockout (KO) male mice as described in the 'Materials and methods' section. The results show the mean glucose concentrations \pm S.E.M.

(Fig. 1H) and male (Fig. 1I) high-fat-fed 129SvEv WT mice revealed surprisingly no increase in FPI.

After 13 weeks of high-fat feeding, a reduction in FBG was observed in both female (Fig. 1F) and male (Fig. 1G)
G6pc2 $\mathrm{KO}$ relative to WT mice with no differences in FPI in either female (Fig. 1H) or male (Fig. 1I) mice relative to WT. http://jme.endocrinology-journals.org DOI: 10.1530/JME-16-0202
() 2017 Society for Endocrinology Printed in Great Britain 


\section{Analysis of the effect of high-fat feeding on glucose tolerance in 129SvEv WT and G6pc2 KO mice}

We have previously shown that deletion of G6pc2 does not affect glucose tolerance in chow-fed C57BL/6J (Pound et al. 2013) and 129SvEv (Boortz et al. 2016) mice, consistent with human GWAS data showing no association between G6PC2 SNPs and variations in glucose tolerance (Li et al. 2009, Rose et al. 2009, Heni et al. 2010, Ingelsson et al. 2010). Although high-fat feeding did not result in weight gain in male $129 \mathrm{SvEv}$ mice (Table 2) relative to chow-fed mice (Table 1), intraperitoneal glucose tolerance tests (IPGTTs) revealed a clear impairment in glucose tolerance in both WT $(P<0.0002)$ and $G 6 p c 2 \mathrm{KO}(P<0.0001)$ highfat fed 129SvEv mice relative to chow-fed mice (Fig. 1J), suggesting the presence of either insulin resistance and/ or impaired GSIS in high-fat-fed 129SvEv mice. However, even in high-fat-fed mice, deletion of G6pc2 did not affect glucose tolerance (Fig. 1H).

\section{Analysis of the effect of G6pc2 deletion on body weight, FBG and FPI in high-fat-fed mixed genetic background mice}

A comparison of data derived from studies on C57BL/6J (Pound et al. 2013) and 129SvEv (Fig. 1, Tables 1 and 2) mice suggest that the effect of G6pc2 deletion on body weight varies with gender and genetic background. We therefore repeated these high-fat feeding analyses in mice with a mixed C57BL/6J X 129SvEv genetic background. We have previously shown that FBG is reduced in both female and male mixed C57BL/6J X 129SvEv genetic background $G 6 p c 2$ KO mice relative to WT with no differences in body weight or FPI (Wang et al. 2007). After starting high-fat feeding at 8 weeks of age and continuing for 8 weeks, we observed no differences in body weight between female mixed genetic background WT and KO mice (Fig. 2A). In contrast, male mixed genetic background G6pc2 $\mathrm{KO}$ mice exhibited a striking protection against DIO (Fig. 2B).

No reduction in FBG was observed in high-fat-fed female $\mathrm{KO}$ mice relative to WT mice (Fig. 2C), whereas FBG was markedly reduced in high-fat-fed male KO mice relative to WT mice (Fig. 2D). Similarly, although no difference in FPI was observed between high-fat-fed female $\mathrm{KO}$ mice relative to WT mice (Fig. 2E), FPI was markedly reduced in high-fat-fed male $\mathrm{KO}$ mice relative to WT mice (Fig. 2F).
A

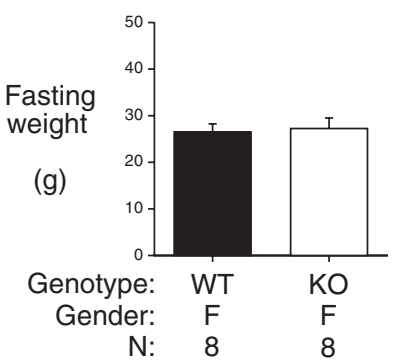

C

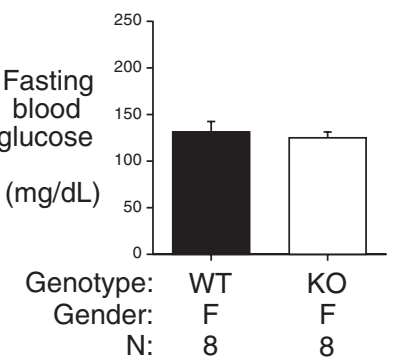

$\mathrm{E}$

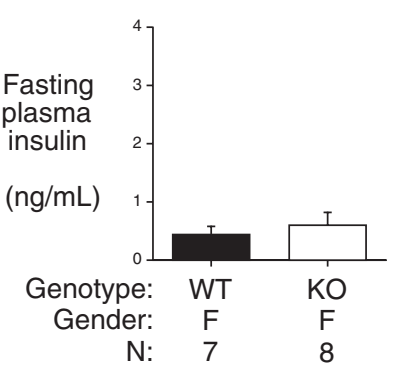

B

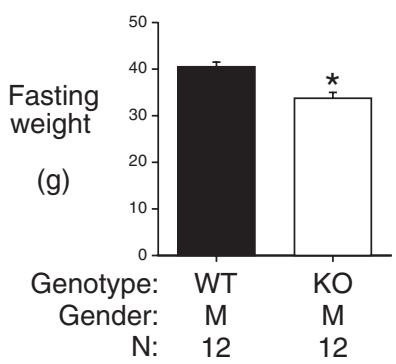

Mixed HFF

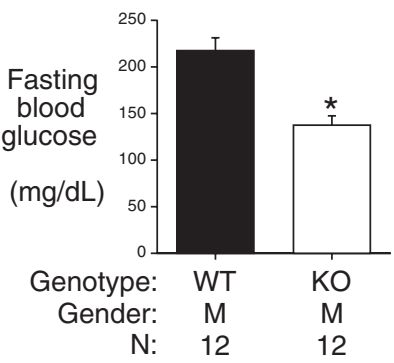

$\mathrm{F}$ Mixed HFF

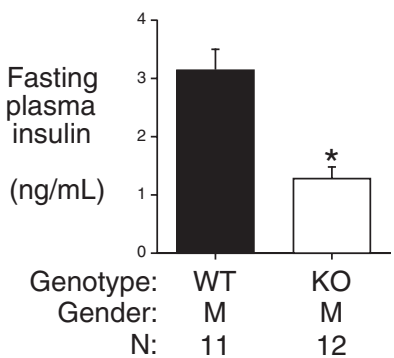

Figure 2

Effect of G6pc2 deletion on body weight and metabolic parameters in high-fat-fed mixed background mice. Metabolic parameters were assessed in high-fat-fed mixed genetic background mice at 16 weeks of age after 8 weeks of high-fat feeding. Mice were fasted for $5 \mathrm{~h}$ and then weighed (Panels A and B). One hour later, mice were anesthetized and blood was isolated. Blood glucose (Panels $C$ and D) and plasma insulin (Panels $\mathrm{E}$ and $\mathrm{F}$ ) were determined as described in the 'Materials and methods' section. Results are the mean \pm S.E.M. of data with the genotype, gender and number of animals indicated. WT, wild type; KO, knockout; $F$, female; M, male. * $P<8.32 \mathrm{E}-05$ WT vs KO (Panel B); ${ }^{*} P<3.45 \mathrm{E}-05$ WT vs KO (Panel D); $* P<6.84 \mathrm{E}-05$ WT vs KO (Panel F).

\section{Comparison of pancreatic G6pc2 expression in 129SvEv and C57BL/6J mice}

The data derived from studies on C57BL/6J, 129SvEv and mixed genetic background mice reveal that the effect of $G 6 p c 2$ deletion on body weight varies with gender and genetic background. In addition, FBG is lower in both male

Published by Bioscientifica Ltd. 
A

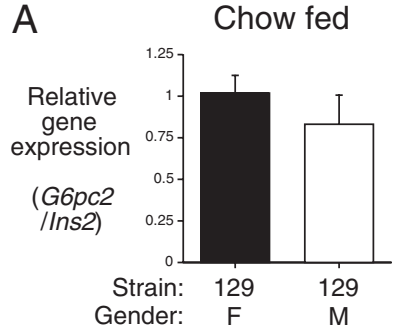

E

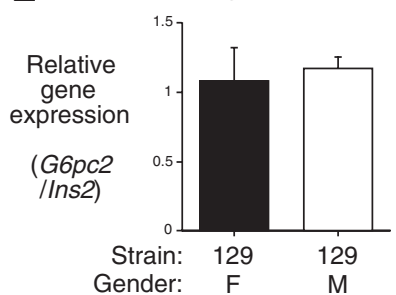

B

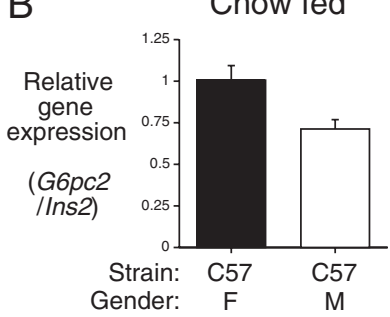

F

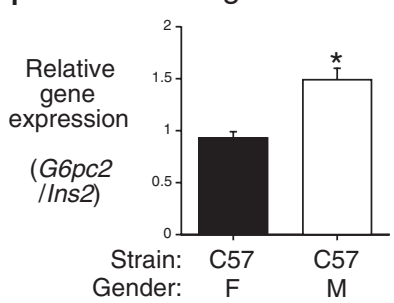

C

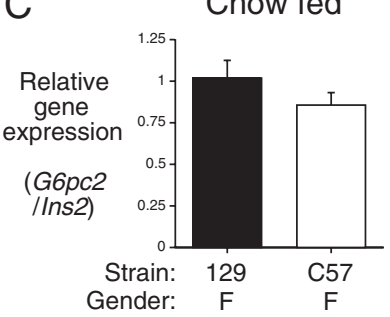

G

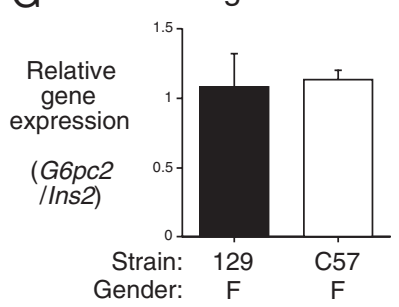

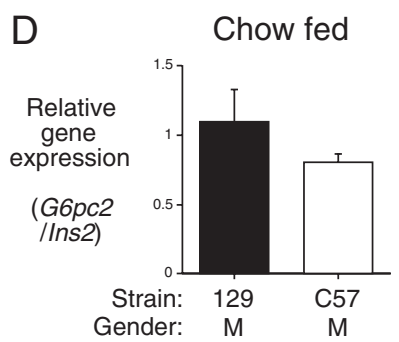

$\mathrm{H}$

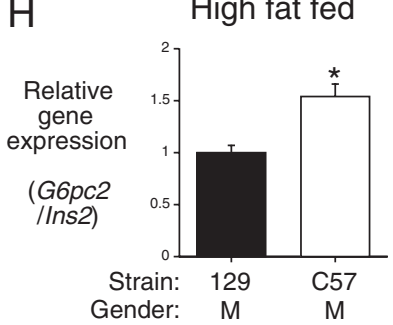

Figure 3

Comparison of pancreatic G6pc2 expression in 129SvEv and C57BL/6J mice. Pancreatic RNA was isolated after a 6-h fast from chow-fed (Panels A, B, C and D) 129SvEv (129) or C57BL/6J (C57) mice or mice fed a high-fat diet for 2 weeks (Panels E, F, G and H). G6pc2 and Ins2 expression were quantitated by real-time PCR. Results show the ratio of G6pc2 to Ins2 expression \pm s.E.M. in 3-5 pancreata. * $P<0.05$ vs control.

chow-fed (Boortz et al. 2016) and high-fat-fed (Fig. 1F) 129SvEv mice than that in C57BL/6J mice (Goren et al. 2004, Mazzaccara et al. 2008, Pound et al. 2013). Although there are likely multiple factors that account for these differences, one potential contributing factor could be variations in $66 p c 2$ gene expression between C57BL/6J and 129SvEv mice. To address this possibility, we compared pancreatic G6pc2 and Ins2 gene expression in both mouse strains. There was no difference in the ratio of $G 6 p c 2$ to Ins 2 gene expression between female and male chow-fed 129SvEv mice (Fig. 3A) or between female and male chowfed C57BL/6J mice (Fig. 3B). There was also no difference in the ratio of $G 6 p c 2$ to Ins2 gene expression between chow-fed female 129SvEv and C57BL/6J mice (Fig. 3C) or between chow-fed male 129SvEv and C57BL/6J mice (Fig. 3D). In contrast, although there was no difference in the ratio of $G 6 p c 2$ to Ins 2 gene expression between female and male high-fat-fed 129SvEv mice (Fig. 3E), there was a difference between female and male high-fatfed C57BL/6J mice (Fig. 3F). Similarly, although there was no difference in the ratio of G6pc2 to Ins2 gene expression between high-fat-fed female 129SvEv and C57BL/6J mice (Fig. 3G), there was a difference between high-fat-fed male 129SvEv and C57BL/6J mice (Fig. 3H). These data suggest that $G 6 p c 2$ expression is induced by high-fat feeding relative to Ins 2 expression in male C57BL/6J mice, which may contribute to differences in the effect of high fat feeding between male and female C57BL/6J mice and between male C57BL/6J and 129SvEv mice.

\section{Analysis of the effect of G6pc2 deletion on plasma cholesterol in 129SvEv, C57BL/6J and mixed genetic background mice}

As multiple plasma lipids change in response to highfat feeding (Eisinger et al. 2014), we also compared plasma cholesterol levels in G6pc2 KO mice on different genetic backgrounds. We previously observed no change in cholesterol levels in male or female mixed genetic background G6pc2 KO mice relative to WT (Wang et al. 2007). However, when we repeated these analyses in chow-fed 129SvEv and C57BL/6J mice along with highfat fed 129SvEv, C57BL/6J and mixed genetic background mice, we observed that plasma cholesterol levels were reduced in chow-fed male C57BL/6J KO mice (Fig. 4D), high-fat-fed female (Fig. 4G) and male (Fig. 4H) C57BL/6J $\mathrm{KO}$ mice and high-fat-fed mixed genetic background male KO mice (Fig. 4J).

\section{Analysis of the relationship between G6PC2 SNPs and metabolic parameters in humans using BioVU}

Our results in mice demonstrate that the effect of $G 6 p c 2$ deletion on cholesterol levels varies with gender and genetic background. We next used Vanderbilt's BioVU DNA databank to determine whether G6PC2 affects these parameters in humans. BioVU individuals with extant genotyping at the intronic G6PC2 SNP rs560887 were screened to identify associations with cholesterol

Published by Bioscientifica Ltd. 
A

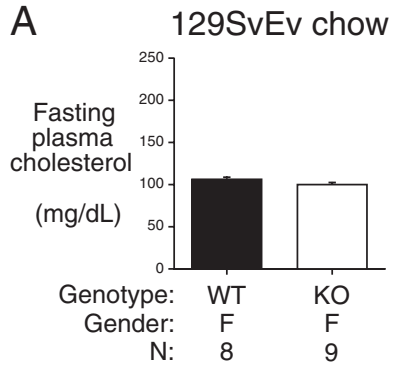

E

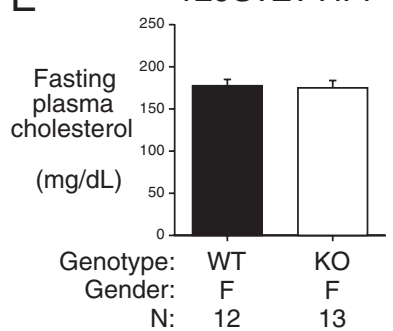

I

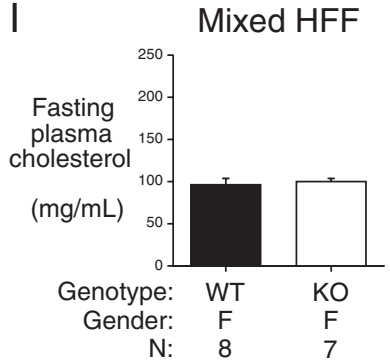

B

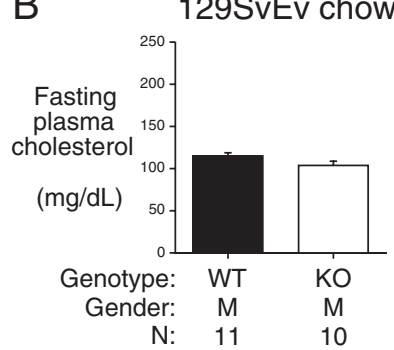

F

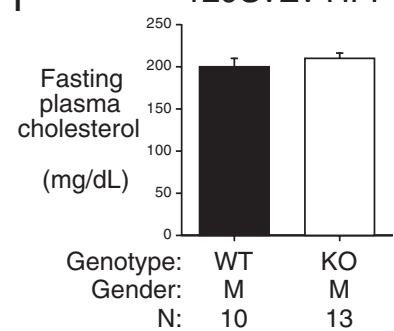

J

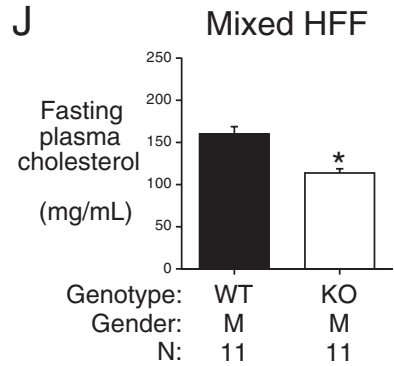

C

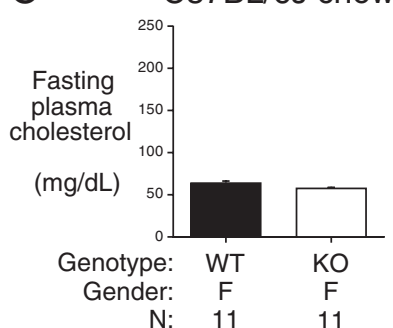

G

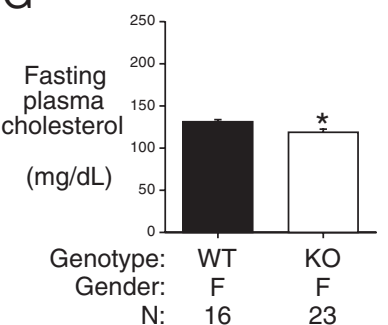

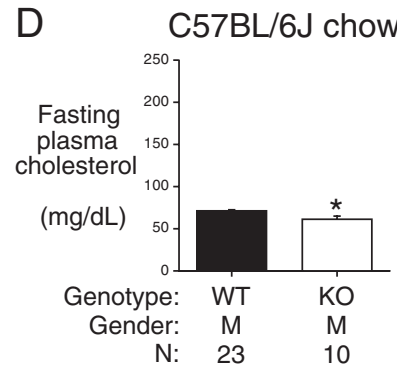

$\mathrm{H}$

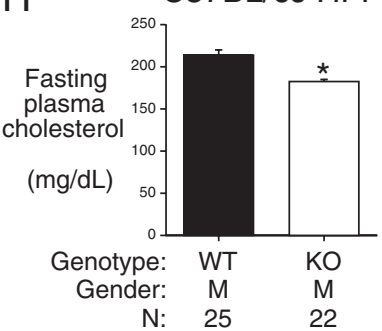

Figure 4

Effect of G6pc2 deletion on plasma cholesterol in 129SvEv, C57BL/6J and mixed genetic background mice. Panels A, B, C and D: At 17 weeks of age, chow-fed 129SvEv or C57BL/6J mice were fasted for $5 \mathrm{~h}$ and then weighed. One hour later, mice were anesthetized and blood was isolated. Panels $\mathrm{E}$, $\mathrm{F}$, $\mathrm{G}$ and $\mathrm{H}$ : At 21 weeks of age, after 13 weeks of high-fat feeding, 129SvEv and C57BL/6J mice were fasted for $5 \mathrm{~h}$ and then weighed. One hour later, mice were anesthetized and blood was isolated. Panels I and J: At 16 weeks of age, following 8 weeks of high-fat feeding, mixed genetic background mice were fasted for $5 \mathrm{~h}$ and then weighed. One hour later, mice were anesthetized and blood was isolated. Plasma cholesterol was determined as described in the 'Materials and methods' section. Results are the mean \pm s.E.M. of data with the genotype, gender and number of animals indicated. WT, wild type; KO, knockout; F, female; M, male. * $P<0.0069$ WT vs KO (Panel D); ${ }^{*}<<0.02$ WT vs KO (Panel G); ${ }^{*}<7.01 \mathrm{E}-06$ WT vs KO (Panel H); $P<0.001$ WT vs KO (Panel J).

and triglyceride measurements. The rs560887-G allele, which enhances G6PC2 pre-mRNA splicing (Baerenwald et al. 2013), was associated with increased cholesterol (total cholesterol: $\beta=1.0, P=0.039$; LDL-C: $\beta=1.1, P=0.006)$, but not triglyceride levels $(\beta=0.90$, $P=0.46)$ or HDL-C $(\beta=-0.07, P=0.75)$ (Table 3$)$. We further analyzed the population by sex and found that rs560887-G significantly associated with increased LDL-C in males $(P=0.009)$ but not in females $(P=0.15)$, although SNP and sex interaction is not significant $(P=0.30)$ (Table 3). Rs560887 did not associate with diabetes status $(P=0.37)$. Thus, as in mice, the impact in humans of modulating G6PC2 expression on plasma lipids is dependent on gender.

\section{Analysis of the effect of G6pc2 deletion on food intake}

A key question that arises from these studies is how G6PC2, which is thought to be expressed exclusively in pancreatic islet beta cells (Arden et al. 1999, Martin et al. 2001), could be affecting body weight. One possible explanation for the link between G6PC2 and body weight is that G6PC2 affects satiety. Thus, the leftward shift in the dose-response curve for GSIS observed in G6pc2 KO mice (Pound et al. 2013) might result in a faster rise in plasma insulin levels after eating or glucose injection in an IPGTT. As insulin is a satiety factor (Woods et al. 2006), this faster rise in insulin could promote a quicker cessation of feeding and ultimately reduced food intake. To address this hypothesis, we measured the intake of high-fat food

Published by Bioscientifica Ltd 
Table 3 Association between G6PC2 SNP rs560887 and plasma lipid measurements using electronic health record (EHR)-derived phenotype analyses.

\begin{tabular}{|c|c|c|c|c|c|c|c|c|}
\hline \multirow[b]{2}{*}{ Lab } & \multirow[b]{2}{*}{ Population } & \multirow[b]{2}{*}{$\boldsymbol{N}$} & \multirow[b]{2}{*}{ Beta (G) } & \multirow[b]{2}{*}{$95 \% \mathrm{Cl}$} & \multirow[b]{2}{*}{$P$-value } & \multicolumn{3}{|c|}{ Allele } \\
\hline & & & & & & GG & GA & AA \\
\hline LDL-C & All & 13,087 & 1.15 & $0.33-1.96$ & 0.006 & $102.13 \pm 31.43$ & $101.58 \pm 31.33$ & $99.08 \pm 31.25$ \\
\hline LDL-C & Male & 5863 & 1.60 & $0.4-2.8$ & 0.009 & $97.5 \pm 31.23$ & $95.77 \pm 29.41$ & $94.29 \pm 32.15$ \\
\hline LDL-C & Female & 7224 & 0.82 & $-0.29-1.93$ & 0.148 & $105.9 \pm 31.09$ & $106.33 \pm 32.05$ & $102.73 \pm 30.07$ \\
\hline Cholesterol & All & 14,349 & 1.00 & 0.05-1.95 & 0.039 & $183.62 \pm 38.55$ & $183.25 \pm 38.96$ & $181.18 \pm 40.03$ \\
\hline Cholesterol & Male & 6412 & 1.49 & $0.09-2.87$ & 0.037 & $173.36 \pm 37.46$ & $171.53 \pm 36.79$ & $170.63 \pm 38.45$ \\
\hline Cholesterol & Female & 7937 & 0.68 & $-0.59-1.95$ & 0.29 & $191.97 \pm 37.39$ & $192.81 \pm 38.06$ & $189.05 \pm 39.39$ \\
\hline Triglycerides & All & 14,213 & 0.90 & $-1.48-3.28$ & 0.459 & $149.92 \pm 98.13$ & $149.41 \pm 95.16$ & $148.37 \pm 99.99$ \\
\hline Triglycerides & Male & 6398 & -0.08 & $-4.07-3.9$ & 0.967 & $157.72 \pm 109.51$ & $157.17 \pm 105.84$ & $157.87 \pm 107.95$ \\
\hline Triglycerides & Female & 7815 & 1.80 & $-1.02-4.62$ & 0.211 & $143.49 \pm 87.14$ & $143.00 \pm 84.82$ & $141.09 \pm 92.86$ \\
\hline HDL-C & All & 13,457 & -0.07 & $-0.46-0.33$ & 0.746 & $51.42 \pm 17.11$ & $51.36 \pm 17.47$ & $51.76 \pm 17.56$ \\
\hline HDL-C & Male & 6006 & 0.28 & $-0.22-0.78$ & 0.269 & $44.00 \pm 13.49$ & $43.54 \pm 12.93$ & $43.72 \pm 13.33$ \\
\hline HDL-C & Female & 7451 & -0.35 & $-0.94-0.24$ & 0.245 & $57.43 \pm 17.38$ & $57.70 \pm 18.09$ & $57.85 \pm 17.93$ \\
\hline
\end{tabular}

Plasma lipid measurements were obtained from routine lipid panels in Vanderbilt University Medical Center's EHR repository. For each laboratory of each individual, the associations are tested against the median of all laboratory results for that test. All associations were adjusted for age, sex and body mass index using linear regression. The unit for all measurements is $\mathrm{mg} / \mathrm{dL}$.

Cholesterol, total cholesterol; HDL-C, calculated high-density lipoprotein; LDL-C, calculated low-density lipoprotein.

in female C57BL/6J WT and G6pc2 KO mice. Although female C57BL/6J G6pc2 KO mice are lighter than wildtype (WT) littermates on both a chow-fed and high-fat-fed diet (Pound et al. 2013), no difference in food intake was detected (Fig. 5).

\section{Discussion}

Our results demonstrate that the effect of G6pc2 deletion in mice on FBG closely parallels human GWAS data in that the effect of G6pc2 deletion on FBG is largely independent of gender and genetic background. We previously showed that, relative to WT mice, FBG is reduced in both female and male chow-fed and high-fat-fed G6pc2 $\mathrm{KO}$ on a pure C57BL/6J genetic background (Pound et al. 2013), female and male chow-fed G6pc2 KO mice on a mixed genetic background (Wang et al. 2007) and male mice on a 129SvEv genetic background (Boortz et al. 2016).
We show here that FBG is also reduced in $129 \mathrm{SvEv}$ chowfed female mice (Fig. 1D) and high-fat-fed female (Fig. 1F) and male (Fig. 1G) mice. Similarly, FBG is reduced in male high-fat-fed mixed genetic background G6pc2 KO relative to WT mice (Fig. 2D). FBG was not reduced in female high-fat-fed mixed genetic background G6pc2 $\mathrm{KO}$ mice (Fig. 2C), though the $\mathrm{n}$ value in this study was relatively low. These observations are largely consistent with human GWAS data showing an association between G6PC2 and FBG in multiple different populations (Prokopenko et al. 2008, Bouatia-Naji et al. 2009, Hu et al. 2009, 2010, Reiling et al. 2009, Dupuis et al. 2010, Tam et al. 2010, Wang et al. 2013).

With respect to FPI, we previously showed that, relative to WT mice, FPI is unchanged in both female and male chow-fed and high-fat-fed G6pc2 KO mice on a pure C57BL/6J genetic background (Pound et al. 2013), female and male chow-fed G6pc2 KO mice on a mixed

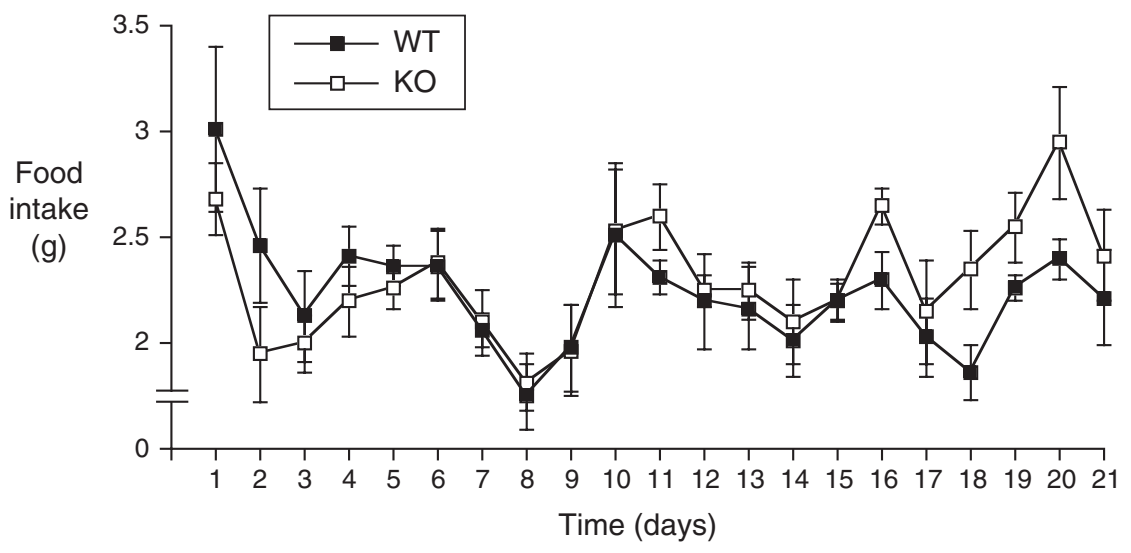

\section{Figure 5}

Effect of G6pc2 deletion on high-fat food intake in female C57BL/6J WT and G6pc2 KO mice. Female C57BL/6J WT and G6pc2 KO mice were switched from chow food to high-fat food at 8 weeks of age, and food intake was measured daily for 21 days. Results show the mean food intake \pm S.E.M. in 6 WT and 6 G6pc2 KO mice. http://jme.endocrinology-journals.org
DOI: 10.1530/JME-16-0202
C 2017 Society for Endocrinology Printed in Great Britain
Published by Bioscientifica Ltd. 
genetic background (Wang et al. 2007) and male mice on a 129SvEv genetic background (Boortz et al. 2016). We show here that FBI is also unchanged in $129 \mathrm{SvEv}$ chowfed female mice (Fig. 1E) and high-fat-fed female (Fig. 1H) and male (Fig. 1I) mice. Similarly, FPI is unchanged in female high-fat-fed mixed genetic background G6pc2 KO mice (Fig. 2E). A reduction in FPI was observed in male high-fat-fed mixed genetic background G6pc2 $\mathrm{KO}$ mice (Fig. 2F), but this is presumably secondary to the marked effect of G6pc2 deletion on body weight in males (Fig. 2B). These observations are consistent with human GWAS data showing no association between G6PC2 and FPI in multiple different populations (Bouatia-Naji et al. 2008, Chen et al. 2008, Mahajan et al. 2015, Wessel et al. 2015).

In contrast to these data showing largely consistent effects of G6pc2 deletion on FBG and FPI regardless of gender, diet and genetic background, the effect of $G 6 p c 2$ deletion on body weight and body composition is highly dependent on these variables. We previously showed that female, but not male, G6pc2 KO mice on a pure C57BL/6J genetic background had reduced body weight and body fat on both a chow- and high-fat diet relative to WT mice (Pound et al. 2013). In contrast, we show here that deletion of G6pc2 in female mice on the 129SvEv genetic background has no effect on body weight or body fat on either a chow (Table 1) or high-fat (Table 2) diet relative to WT mice. Similarly, deletion of G6pc2 in female mice on a mixed 129SvEv X C57BL/6J genetic background has no effect on body weight on either a chow (Wang et al. 2007) or high-fat (Fig. 2A) diet relative to WT mice. In males, deletion of G6pc2 on the 129SvEv genetic background was associated with reduced body weight on a chow diet (Table 1) but increased body weight on a high-fat diet (Table 2). In contrast, deletion of G6pc2 in male mice on a mixed 129SvEv X C57BL/6J genetic background had no effect on body weight on a chow diet (Wang et al. 2007), whereas this conferred a marked protection against DIO on a high-fat diet (Fig. 2B). Overall, our results suggest that FBG is a much more tightly regulated variable than body weight. Thus, although FBG levels are relatively similar in chow-fed C57BL/6J (Pound et al. 2013), 129SvEv (Boortz et al. 2016) and mixed (Wang et al. 2007) genetic background mice, the increase in body weight and body fat in response to high-fat feeding is markedly different in C57BL/6J (Surwit et al. 1988, Winzell \& Ahren 2004, Pound et al. 2013) and 129SvEv mice (Fig. 1) (Almind $\&$ Kahn 2004). Interestingly, the response to DIO varies remarkably even within inbred mice through poorly understood epigenetic mechanisms (Burcelin et al. 2002,
Koza et al. 2006, Oey et al. 2015) though whether such mechanisms and/or environmental factors or modifier genes contribute to the variable effects of G6pc2 deletion on body weight and composition is unknown.

In humans, a GWAS performed in a cohort of Mexican Americans linked the G6PC2 rs560887-A allele with a small decrease in BMI and adiposity in this population (Li et al. 2009); however, other GWAS have not associated G6PC2 with variations in body mass index, fat mass or fat distribution (Lu et al. 2016). Similarly, a strong association between G6PC2 and cholesterol was not detected using GWAS (Aulchenko et al. 2009, Kathiresan et al. 2009), though a weak association can be detected using BioVU (Table 3). These observations suggest that either the effects of G6pc2 on body mass and cholesterol are quantitatively only easily detected in mice on specific genetic backgrounds or that there is a threshold effect such that G6PC2 will markedly affect these parameters in some human populations but only after a substantial change in expression rather than the subtle changes associated with common SNPs (Bouatia-Naji et al. 2010, Baerenwald et al. 2013). If correct, the association observed by GWAS between common SNPs in G6PC2 and subclinical atherosclerosis (Rasmussen-Torvik et al. 2011) is likely secondary to the effect of G6PC2 on FBG rather than a direct effect of G6PC2 on cholesterol metabolism.

A key question that remains to be addressed is how G6PC2, which is thought to be expressed exclusively in pancreatic islet beta cells (Arden et al. 1999, Martin et al. 2001), could be affecting body weight. One possibility, as proposed by Li and coworkers (Li et al. 2009), is that the differences in body weight they observed in humans are secondary effects due to altered insulin signaling efficacy that arise due to an effect of G6PC2 on the pulsatility of insulin secretion. Another possibility is that G6PC2 expression in other tissues that affect body weight has been overlooked. Indeed although RNA blotting showed no evidence for G6PC2 expression in brain (Martin et al. 2001) and transgenic mouse studies gave inconsistent results (Frigeri et al. 2004, Wang et al. 2008), one group has reported G6pc2 expression in the mouse hypothalamus (Goh et al. 2006), a region critical for the control of body weight (Morton et al. 2006). However, this expression was only detected using very high template concentrations and PCR cycles (Goh et al. 2006). Moreover, although low levels of expression were detected, it is unlikely to be biologically consequential as expression of the $G 6 p c 3$ isoform was detected at much higher levels (Goh et al. 2006) and G6pc3 is http://jme.endocrinology-journals.org DOI: 10.1530/JME-16-0202
() 2017 Society for Endocrinology Printed in Great Britain
Published by Bioscientifica Ltd 
enzymatically more active than G6pc2 (Shieh et al. 2003, Petrolonis et al. 2004). One other potential explanation for the link between G6PC2 and body weight is that G6PC2 affects satiety. Thus, the leftward shift in the dose-response curve for GSIS observed in G6pc2 KO mice (Pound et al. 2013) might result in a faster rise in plasma insulin levels after eating. As insulin is a satiety factor (Woods et al. 2006), this faster rise in insulin could promote a quicker cessation of feeding and ultimately reduced food intake. However, an analysis of food intake did not detect a difference between female C57BL/6J WT and G6pc2 KO mice (Fig. 5). Future studies will examine the alternate possibility, specifically whether deletion of $G 6 p c 2$ affects energy expenditure (Ellacott et al. 2010). Although food intake did not differ between C57BL/6J WT and G6pc2 KO mice, an effect of G6PC2 on the timing of GSIS during glucose tolerance tests could explain the counterintuitive observation that the rs560887-G allele, which confers elevated G6PC2 expression (Baerenwald et al. 2013), is associated with elevated FBG but also higher insulin levels at the 30-min time point in a glucose tolerance test (Li et al. 2009). We hypothesize that insulin levels may peak earlier in individuals with the rs560887-A allele, which confers lower G6PC2 expression (Baerenwald et al. 2013).

\section{Declaration of interest}

$\mathrm{R} \mathrm{O}^{\prime} \mathrm{B}$ is the guarantor of this work, had full access to all the data, and takes full responsibility for the integrity of data and the accuracy of data analysis. None of the authors have a conflict of interest relating to this study.

\section{Funding}

This research was supported by the following grants: R O'B, DK92589; O P M, DK043748 and DK078188; J C D, LM010685. The measurement of plasma insulin by the Vanderbilt Hormone Assay \& Analytical Services Core was supported by NIH grant P60 DK20593, to the Vanderbilt Diabetes Research Training Center. The measurement of body composition using the Vanderbilt Mouse Metabolic Phenotyping Center mq10 NMR analyzer was supported by NIH grant DK59637. K E S and L D P were supported by the Vanderbilt Molecular Endocrinology Training Program grant 5T32 DK07563.

\section{Author contribution statement}

$\mathrm{K} A \mathrm{~B}$ performed most of the mouse phenotyping studies and manuscript writing. K E S performed some of the mouse studies. L D P performed some of the mouse studies. H M performed association studies with EHR data and manuscript editing. L B performed association studies with EHR data. J K O performed some of the mouse studies. O P M contributed to the design of experiments and manuscript editing. J C D contributed to design of EHR studies and manuscript editing. $\mathrm{R} \mathrm{M} \mathrm{O} \mathrm{performed} \mathrm{some} \mathrm{of}$ the mouse studies and manuscript writing.

\section{Acknowledgements}

The authors thank Susan Hajizadeh for performing insulin assays and Devin A Baerenwald for assistance with the food intake study.

\section{References}

Almind K \& Kahn CR 2004 Genetic determinants of energy expenditure and insulin resistance in diet-induced obesity in mice. Diabetes $\mathbf{5 3}$ 3274-3285. (doi:10.2337/diabetes.53.12.3274)

Arden SD, Zahn T, Steegers S, Webb S, Bergman B, O'Brien RM \& Hutton JC 1999 Molecular cloning of a pancreatic islet-specific glucose-6-phosphatase catalytic subunit-related protein. Diabetes $\mathbf{4 8}$ 531-542. (doi:10.2337/diabetes.48.3.531)

Aulchenko YS, Ripatti S, Lindqvist I, Boomsma D, Heid IM, Pramstaller PP, Penninx BW, Janssens AC, Wilson JF, Spector T, et al. 2009 Loci influencing lipid levels and coronary heart disease risk in 16 European population cohorts. Nature Genetics 41 47-55. (doi:10.1038/ng.269)

Baerenwald DA, Bonnefond A, Bouatia-Naji N, Flemming BP, Umunakwe OC, Oeser JK, Pound LD, Conley NL, Cauchi S, Lobbens S, et al. 2013 Multiple functional polymorphisms in the G6PC2 gene contribute to the association with higher fasting plasma glucose levels. Diabetologia 56 1306-1316. (doi:10.1007/s00125-013-2875-3)

Boortz KA, Syring KE, Dai C, Pound LD, Oeser JK, Jacobson DA, Wang JC, McGuinness OP, Powers AC \& O’Brien RM 2016 G6PC2 modulates fasting blood glucose in male mice in response to stress. Endocrinology 157 3002-3008. (doi:10.1210/en.2016-1245)

Bouatia-Naji N, Rocheleau G, Van Lommel L, Lemaire K, Schuit F, Cavalcanti-Proenca C, Marchand M, Hartikainen AL, Sovio U, De Graeve F, et al. 2008 A polymorphism within the G6PC2 gene is associated with fasting plasma glucose levels. Science 320 1085-1088. (doi:10.1126/science.1156849)

Bouatia-Naji N, Bonnefond A, Cavalcanti-Proenca C, Sparso T, Holmkvist J, Marchand M, Delplanque J, Lobbens S, Rocheleau G, Durand E, et al. 2009 A variant near MTNR1B is associated with increased fasting plasma glucose levels and type 2 diabetes risk. Nature Genetics 41 89-94. (doi:10.1038/ng.277)

Bouatia-Naji N, Bonnefond A, Baerenwald DA, Marchand M, Bugliani M, Marchetti P, Pattou F, Printz RL, Flemming BP, Umunakwe OC, et al. 2010 Genetic and functional assessment of the role of the rs13431652-A and rs573225-A alleles in the G6PC2 promoter that strongly associate with elevated fasting glucose levels. Diabetes 59 2662-2671. (doi:10.2337/db10-0389)

Burcelin R, Crivelli V, Dacosta A, Roy-Tirelli A \& Thorens B 2002 Heterogeneous metabolic adaptation of C57BL/6J mice to high-fat diet. American Journal of Physiology: Endocrinology and Metabolism 282 E834-E842. (doi.org/10.1152/ajpendo.00332.2001)

Chen WM, Erdos MR, Jackson AU, Saxena R, Sanna S, Silver KD, Timpson NJ, Hansen T, Orru M, Grazia Piras M, et al. 2008 Variations in the G6PC2/ABCB11 genomic region are associated with fasting glucose levels. Journal of Clinical Investigation 118 2620-2628. (doi:10.1172/JCI32723)

Dupuis J, Langenberg C, Prokopenko I, Saxena R, Soranzo N, Jackson AU, Wheeler E, Glazer NL, Bouatia-Naji N, Gloyn AL, et al. 2010 New genetic loci implicated in fasting glucose homeostasis and their impact on type 2 diabetes risk. Nature Genetics 42 105-116. (doi:10.1038/ng.520)

Ebert DH, Bischof LJ, Streeper RS, Chapman SC, Svitek CA, Goldman JK, Mathews CE, Leiter EH, Hutton JC \& O’Brien RM 1999 Structure and promoter activity of an islet-specific glucose-6- phosphatase catalytic subunit-related gene. Diabetes 48 543-551. (doi:10.2337/ diabetes.48.3.543)

Eisinger K, Liebisch G, Schmitz G, Aslanidis C, Krautbauer S \& Buechler C 2014 Lipidomic analysis of serum from high fat diet

Published by Bioscientifica Ltd. 
induced obese mice. International Journal of Molecular Sciences $\mathbf{1 5}$ 2991-3002. (doi:10.3390/ijms15022991)

Ellacott KL, Morton GJ, Woods SC, Tso P \& Schwartz MW 2010 Assessment of feeding behavior in laboratory mice. Cell Metabolism 12 10-17. (doi:10.1016/j.cmet.2010.06.001)

Frigeri C, Martin CC, Svitek CA, Oeser JK, Hutton JC, Gannon M \& O'Brien RM 2004 The proximal islet-specific glucose-6-phosphatase catalytic subunit related protein (IGRP) autoantigen promoter is sufficient to initiate but not maintain transgene expression in mouse islets in vivo. Diabetes 53 1754-1764. (doi:10.2337/ diabetes.53.7.1754)

Goh BH, Khan A, Efendic S \& Portwood N 2006 Expression of glucose-6phosphatase system genes in murine cortex and hypothalamus. Hormone and Metabolic Research 38 1-7. (doi:10.1055/s-2006-924964)

Goren HJ, Kulkarni RN \& Kahn CR 2004 Glucose homeostasis and tissue transcript content of insulin signaling intermediates in four inbred strains of mice: C57BL/6, C57BLKS/6, DBA/2, and 129X1. Endocrinology 145 3307-3323. (doi:10.1210/en.2003-1400)

Heni M, Ketterer C, t Hart LM, Ranta F, van Haeften TW, Eekhoff EM, Dekker JM, Boomsma DI, Nijpels G, Kramer MH, et al. 2010 The impact of genetic variation in the G6PC2 gene on insulin secretion depends on glycemia. Journal of Clinical Endocrinology and Metabolism 95 E479-E484. (doi:10.1210/jc.2010-0860)

Hu C, Zhang R, Wang C, Ma X, Wang C, Fang Q, Bao Y, Xiang K \& Jia W 2009 A genetic variant of G6PC2 is associated with type 2 diabetes and fasting plasma glucose level in the Chinese population. Diabetologia 52 451-456. (doi:10.1007/s00125-008-1241-3)

Hu C, Zhang R, Wang C, Yu W, Lu J, Ma X, Wang J, Jiang F, Tang S, Bao Y, et al. 2010 Effects of GCK, GCKR, G6PC2 and MTNR1B variants on glucose metabolism and insulin secretion. PLOS ONE $\mathbf{5}$ e11761. (doi:10.1371/journal.pone.0011761)

Hutton JC \& O'Brien RM 2009 The glucose-6-phosphatase catalytic subunit gene family. Journal of Biological Chemistry 284 29241-29245. (doi:10.1074/jbc.R109.025544)

Ingelsson E, Langenberg C, Hivert MF, Prokopenko I, Lyssenko V, Dupuis J, Magi R, Sharp S, Jackson AU, Assimes TL, et al. 2010 Detailed physiologic characterization reveals diverse mechanisms for novel genetic Loci regulating glucose and insulin metabolism in humans. Diabetes 59 1266-1275. (doi:10.2337/db09-1568)

Iynedjian PB 2009 Molecular physiology of mammalian glucokinase. Cellular and Molecular Life Sciences 66 27-42. (doi:10.1007/s00018008-8322-9)

Kathiresan S, Willer CJ, Peloso GM, Demissie S, Musunuru K, Schadt EE, Kaplan L, Bennett D, Li Y, Tanaka T, et al. 2009 Common variants at 30 loci contribute to polygenic dyslipidemia. Nature Genetics $\mathbf{4 1}$ 56-65. (doi:10.1038/ng.291)

Koza RA, Nikonova L, Hogan J, Rim JS, Mendoza T, Faulk C, Skaf J \& Kozak LP 2006 Changes in gene expression foreshadow diet-induced obesity in genetically identical mice. PLoS Genetics 2 e81. (doi:10.1371/journal.pgen.0020081)

Li X, Shu YH, Xiang AH, Trigo E, Kuusisto J, Hartiala J, Swift AJ, Kawakubo M, Stringham HM, Bonnycastle LL, et al. 2009 Additive effects of genetic variation in Gck and G6pc2 on insulin secretion and fasting glucose. Diabetes 58 2946-2953. (doi:10.2337/db09-0228)

Lu Y, Day FR, Gustafsson S, Buchkovich ML, Na J, Bataille V, Cousminer DL, Dastani Z, Drong AW, Esko T, et al. 2016 New loci for body fat percentage reveal link between adiposity and cardiometabolic disease risk. Nature Communications 710495. (doi:10.1038/ncomms10495)

Mahajan A, Sim X, Ng HJ, Manning A, Rivas MA, Highland HM, Locke AE, Grarup N, Im HK, Cingolani P, et al. 2015 Identification and functional characterization of G6PC2 coding variants influencing glycemic traits define an effector transcript at the G6PC2-ABCB11 locus. PLoS Genetics 11 e1004876. (doi:10.1371/ journal.pgen.1004876)
Martin CC, Bischof LJ, Bergman B, Hornbuckle LA, Hilliker C, Frigeri C, Wahl D, Svitek CA, Wong R, Goldman JK, et al. 2001 Cloning and characterization of the human and rat islet-specific glucose-6phosphatase catalytic subunit-related protein (IGRP) genes. Journal of Biological Chemistry 276 25197-25207. (doi:10.1074/jbc.M101549200)

Matschinsky FM 2005 Glucokinase, glucose homeostasis, and diabetes mellitus. Current Diabetes Reports 5 171-176. (doi:10.1007/s11892005-0005-4)

Mazzaccara C, Labruna G, Cito G, Scarfo M, De Felice M, Pastore L \& Sacchetti L 2008 Age-related reference intervals of the main biochemical and hematological parameters in C57BL/6J, 129SV/EV and C3H/HeJ mouse strains. PLoS ONE 3 e3772. (doi:10.1371/ journal.pone.0003772)

Morgan CR \& Lazarow AL 1963 Immunoassay of insulin: two antibody system: plasma insulin of normal, subdiabetic, and diabetic rats. American Journal of the Medical Sciences 257 415-419.

Morton GJ, Cummings DE, Baskin DG, Barsh GS \& Schwartz MW 2006 Central nervous system control of food intake and body weight. Nature 443 289-295. (doi:10.1038/nature05026)

O'Brien RM 2013 Moving on from GWAS: functional studies on the G6PC2 gene implicated in the regulation of fasting blood glucose Current Diabetes Reports 13 768-777. (doi:10.1007/s11892-0130422-8)

Oey H, Isbel L, Hickey P, Ebaid B \& Whitelaw E 2015 Genetic and epigenetic variation among inbred mouse littermates: identification of inter-individual differentially methylated regions. Epigenetics and Chromatin 8 54. (doi:10.1186/s13072-015-0047-z)

Petrolonis AJ, Yang Q, Tummino PJ, Fish SM, Prack AE, Jain S, Parsons TF, Li P, Dales NA, Ge L, et al. 2004 Enzymatic characterization of the pancreatic islet-specific glucose-6phosphatase-related protein (IGRP). Journal of Biological Chemistry 279 13976-13983. (doi:10.1074/jbc.M307756200)

Pound LD, Sarkar SA, Ustione A, Dadi PK, Shadoan MK, Lee CE, Walters JA, Shiota M, McGuinness OP, Jacobson DA, et al. 2012 The physiological effects of deleting the mouse slc30a8 gene encoding zinc transporter-8 are influenced by gender and genetic background. PLOS ONE 7 e40972. (doi:10.1371/journal.pone.0040972)

Pound LD, Oeser JK, O'Brien TP, Wang Y, Faulman CJ, Dadi PK, Jacobson DA, Hutton JC, McGuinness OP, Shiota M, et al. 2013 G6PC2: a negative regulator of basal glucose-stimulated insulin secretion. Diabetes 62 1547-1556. (doi:10.2337/db12-1067)

Prokopenko I, Langenberg C, Florez JC, Saxena R, Soranzo N, Thorleifsson G, Loos RJ, Manning AK, Jackson AU, Aulchenko Y, et al. 2008 Variants in MTNR1B influence fasting glucose levels. Nature Genetics 41 77-81. (doi:10.1038/ng.290)

Pulley J, Clayton E, Bernard GR, Roden DM \& Masys DR 2010 Principles of human subjects protections applied in an opt-out, de-identified biobank. Clinical and Translational Science 3 42-48. (doi:10.1111/j.1752-8062.2010.00175.x)

Rasmussen-Torvik LJ, Li M, Kao WH, Couper D, Boerwinkle E, Bielinski SJ, Folsom AR \& Pankow JS 2011 Association of a fasting glucose genetic risk score with subclinical atherosclerosis: The Atherosclerosis Risk in Communities (ARIC) study. Diabetes 60 331-335. (doi:10.2337/db10-0839)

Reiling E, van 't Riet E, Groenewoud MJ, Welschen LM, van Hove EC, Nijpels G, Maassen JA, Dekker JM \& t Hart LM 2009 Combined effects of single-nucleotide polymorphisms in GCK, GCKR, G6PC2 and MTNR1B on fasting plasma glucose and type 2 diabetes risk. Diabetologia 52 1866-1870. (doi:10.1007/s00125-009-1413-9)

Roden DM, Pulley JM, Basford MA, Bernard GR, Clayton EW, Balser JR \& Masys DR 2008 Development of a large-scale de-identified DNA biobank to enable personalized medicine. Clinical Pharmacology and Therapeutics 84 362-369. (doi:10.1038/clpt.2008.89)

Rose CS, Grarup N, Krarup NT, Poulsen P, Wegner L, Nielsen T, Banasik K, Faerch K, Andersen G, Albrechtsen A, et al. 2009 A http://jme.endocrinology-journals.org

DOI: 10.1530/JME-16-0202
() 2017 Society for Endocrinology Printed in Great Britain
Published by Bioscientifica Ltd 
variant in the G6PC2/ABCB11 locus is associated with increased fasting plasma glucose, increased basal hepatic glucose production and increased insulin release after oral and intravenous glucose loads. Diabetologia 52 2122-2129. (doi:10.1007/s00125-0091463-z)

Shieh JJ, Pan CJ, Mansfield BC \& Chou JY 2003 A glucose-6-phosphate hydrolase, widely expressed outside the liver, can explain agedependent resolution of hypoglycemia in glycogen storage disease type Ia. Journal of Biological Chemistry 278 47098-47103. (doi:10.1074/jbc.M309472200)

Surwit RS, Kuhn CM, Cochrane C, McCubbin JA \& Feinglos MN 1988 Diet-induced type II diabetes in C57BL/6J mice. Diabetes 37 1163-1167. (doi:10.2337/diab.37.9.1163)

Tam CH, Ho JS, Wang Y, Lee HM, Lam VK, Germer S, Martin M, So WY, Ma RC, Chan JC, et al. 2010 Common polymorphisms in MTNR1B, G6PC2 and GCK are associated with increased fasting plasma glucose and impaired beta-cell function in Chinese subjects. PLoS ONE 5 e11428. (doi:10.1371/journal.pone.0011428)

Wall ML, Pound LD, Trenary I, O'Brien RM \& Young JD 2015 Novel stable isotope analyses demonstrate significant rates of glucose cycling in mouse pancreatic islets. Diabetes 64 2129-2137. (doi:10.2337/db14-0745)

Wang Y, Martin CC, Oeser JK, Sarkar S, McGuinness OP, Hutton JC \& O'Brien RM 2007 Deletion of the gene encoding the islet-specific glucose-6-phosphatase catalytic subunit-related protein autoantigen results in a mild metabolic phenotype. Diabetologia 50 774-778. (doi:10.1007/s00125-006-0564-1)
Wang Y, Flemming BP, Martin CC, Allen SR, Walters J, Oeser JK, Hutton JC \& O'Brien RM 2008 Long-range enhancers are required to maintain expression of the autoantigen islet-specific glucose-6phosphatase catalytic subunit-related protein in adult mouse islets in vivo. Diabetes 57 133-141. (doi:10.2337/db07-0092)

Wang H, Liu L, Zhao J, Cui G, Chen C, Ding H \& Wang DW 2013 Large scale meta-analyses of fasting plasma glucose raising variants in GCK, GCKR, MTNR1B and G6PC2 and their impacts on type 2 diabetes mellitus risk. PLOS ONE $\mathbf{8}$ e67665. (doi:10.1371/journal. pone.0067665)

Wessel J, Chu AY, Willems SM, Wang S, Yaghootkar H, Brody JA, Dauriz M, Hivert MF, Raghavan S, Lipovich L, et al. 2015 Lowfrequency and rare exome chip variants associate with fasting glucose and type 2 diabetes susceptibility. Nature Communications 6 5897. (doi:10.1038/ncomms6897)

Winzell MS \& Ahren B 2004 The high-fat diet-fed mouse: a model for studying mechanisms and treatment of impaired glucose tolerance and type 2 diabetes. Diabetes 53 (Supplement 3) S215-S219. (doi:10.2337/diabetes.53.suppl_3.S215)

Woods SC, Lutz TA, Geary N \& Langhans W 2006 Pancreatic signals controlling food intake; insulin, glucagon and amylin. Philosophical Transactions of the Royal Society B: Biological Sciences 361 1219-1235. (doi:10.1098/rstb.2006.1858)

Young GS \& Kirkland JB 2007 Rat models of caloric intake and activity: relationships to animal physiology and human health. Applied Physiology, Nutrition, and Metabolism 32 161-176. (doi:10.1139/h06082)

Received in final form 13 January 2017

Accepted 24 January 2017

Accepted Preprint published online 24 January 2017 (c) 2017 Society for Endocrinology Printed in Great Britain
Published by Bioscientifica Ltd 